\title{
Therapeutic Microinjection of Autologous Adult Human Neural Stem Cells and Differentiated Neurons for Parkinson's Disease: Five-Year Post-Operative Outcome
}

\author{
Michel F. Lévesque ${ }^{1,2,3, *}$, Toomas Neuman ${ }^{3}$ and Michael Rezak ${ }^{2,4}$
}

${ }^{I}$ Cedars-Sinai Medical Center and UCLA School of Medicine and Brain Research Institute, UCLA, Los Angeles, California, USA; ${ }^{2}$ Movement Disorders Program, Los Angeles Neurosurgical Institute, Los Angeles, California, USA; ${ }^{3}$ Neural Transplantation and Molecular Biology Laboratories, NeuroGeneration, Inc, Los Angeles, California, USA and ${ }^{4}$ Feinberg School of Medicine, Northwestern University, Chicago, Illinois, USA

\begin{abstract}
Object. Neural stem cell-derived neurons offer new cellular therapeutic alternatives for diseases of the central nervous system. Selective neural repair can be particularly valuable in progressive degenerative diseases with discrete cell loss, like Parkinson's disease. Some benefits were previously demonstrated following transplantation of fetal embryonic tissue. This approach, however, carries inherent risks of immunological reactions, infectious transmission, and intractable dyskinesias, in addition to serious ethical concerns.

Methods. Cortical and subcortical tissue samples were obtained during neurosurgical procedures. Neural stem cells were isolated and expanded in vitro for several months. Safety, differentiation and functional studies were performed during the expansion phases. Nine months after harvesting, autologous cell suspensions containing differentiated dopaminergic and GABAergic neurons were microinjected unilaterally in a patient with advanced Parkinson's disease. 18F-dopa PET studies and neurological evaluations were performed serially (pre/post-operatively).

Results. Over the next 36 months, the overall Unified Parkinson's Disease Rating Scale (UPDRS) improved by $81 \%$ while "on" medication and $83 \%$ while "off" medication. At five-years post-operatively, clinical motor scores returned to baseline. At three and twelve months post-operatively, 18F-dopa PET studies showed a $55.6 \%$ and $33.2 \%$ increase in dopamine uptake in the implanted left putamen.

Conclusions. Adult neural stem cells derived from a patient's cerebral tissue can become a source of differentiated neurons, useful for grafting in the treatment of Parkinson's disease. The combined GABAergic and dopaminergic cells produced a long lasting motor improvement. This approach has the potential to make neural stem cell therapy acceptable and available to a large number of patients.
\end{abstract}

Key Words: Neural stem cell, Parkinson's disease, Autologous stem cell transplantation, Adult stem cells, Cellular therapy, Clinical translation.

\section{INTRODUCTION}

The progressive loss of midbrain dopaminergic neurons innervating the striatum is the major cause of idiopathic Parkinson's Disease [1-3]. Cellular striatal transplants using human fetal mesencephalic tissue provide some clinical benefits [4-6], but carry inherent risks of immunological reaction [7-9], uncontrolled dyskinesias [10], risks of infectious transmission, in addition to ethical concerns [11]. The identification of neural stem cells (progenitor cells) in the adult brain [12-15] was followed by several studies demonstrating the feasibility of propagating adult human neural stem cells in vitro [16-19].

Neural transplantation in Parkinson's disease (PD) is based on the assumption that grafted cells will supply dopa-

\footnotetext{
*Address correspondence to this author at the Los Angeles Neurosurgical Institute, 8670 Wilshire Blvd., Suite 201, Los Angeles, California, 90211, USA; Tel: (310) 659-6633; Fax: (310) 659-6631;

E-mail: levesque@lansi.org
}

mine to substitute for the lost nigrostriatal neurons [20, 21]. We have harvested neural progenitor stem cells from several patients' prefrontal cortical-subcortical region during craniotomy and succeeded in inducing their differentiation into dopamine-secreting neurons [22]. In this report, we present the long-term clinical results following the autologous transplantation of differentiated neural stem cell-derived neurons unilaterally into a patient with Parkinson's disease.

\section{MATERIALS AND METHODOLOGY}

\section{Clinical Material}

This 57-year old right-handed patient was diagnosed with idiopathic Parkinson's disease at age 46. Family history was negative for neurodegenerative disorders. He received medical therapy with dopaminergic agents with mild initial improvement of his symptoms of rigidity, bradykinesia and tremor. His Hoehn and Yahr stage was 4 while "off" (at least 12 hours drug-free) and 2.5 while "on" ( 1 hour after the usual morning medication) at the time of enrolment in this study. 
The equivalent daily intake of levodopa was $600 \mathrm{mg} /$ day. The tremor involving the right extremities became severely disabling and refractory to any increases in medication or changes in medical therapy. The tremor was initially controlled with the insertion of a left thalamic stimulator into the ventro-intermediate nucleus of the thalamus. During this procedure, a small cylindrical biopsy was obtained, (approximately $90 \mathrm{~mm}^{3}$ ), sampling the prefrontal cortical and subcortical region along the trajectory of the electrode implant. Cedars-Sinai Medical Center Institutional Review Board approved this study and the patient gave informed consent.

\section{Neural Stem Cell Harvesting and Tissue Culture}

Specimens were obtained in accordance with the CedarsSinai Medical Center Institutional Review Board. Biopsies were placed in sterile ice-cold DMEM/F-12 (GIBCO) containing penicillin-streptomycin, for further dissection. The tissue was cut into small pieces and trypsinized $(0.02 \mathrm{mg} / \mathrm{ml}$ trypsin in Verseen (GIBCO) at $37{ }^{\circ} \mathrm{C}$ for 10 minutes). After adding trypsin inhibitor mixture (Clonetics), tissues were mechanically triturated. Cell suspensions were centrifuged at $400 \mathrm{rpm}$ for 5 minutes; pellets were washed once with DMEM/F-12 and plated at density of 5000-10,000 viable cells/ml in the media composed of DMEM/F-12, B27 supplement (GIBCO) and growth factors bFGF (20 ng/ml; Peprotech), EGF (20 ng/ml; Peprotech).

\section{Cell Expansion}

Following their isolation, human neural stem cells were grown in F12/DMEM serum free media (GIBCO), supplemented with B27 growth supplement (GIBCO), 20ng/ml of human recombinant bFGF and EGF. Neural stem cells were grown as neurospheres in $25 \mathrm{~cm}^{2}$ or $75 \mathrm{~cm}^{2}$ Falcon tissue culture flasks; media was changed every second day, and spheres were dissociated by mechanical trituration after every 12 - 15 days. Cell lines were expanded over 6 months.

\section{Cell Differentiation (Test Differentiation)}

Cells were plated onto poly-ornithine coated tissue culture dishes in F12/DMEM serum free medium (GIBCO), supplemented with B27 growth supplement (GIBCO), 10-6 $\mathrm{M}$ all-trans retinoic acid, $1 \mathrm{mM}$ dibutyryl cyclic AMP, FGF8 $(20 \mathrm{ng} / \mathrm{ml})$, and GDNF $(20 \mathrm{ng} / \mathrm{ml})$ and cultured 14 days to promote post-mitotic neurons formation and dopaminergic phenotype differentiation. Before plating, cells were dissociated into smaller aggregates (50-200 cells) and single cells by mechanical trituration in growth media. Immunological staining using antibodies against tyrosine hydroxylase (TH) and dopa decarboxylase (DDC) were used to evaluate dopaminergic differentiation. Additionally, dopamine secretion was evaluated using HPLC analyses. These studies provide an approximate profile of the final cell suspension to be introduced by microinjection after the initiation of differentiation at the time of implantation.

\section{Immunostaining}

Cell cultures were fixed for $20 \mathrm{~min}$ at room temperature with 4\% paraformaldehyde in PBS, washed 3 times in PBS, $\mathrm{pH}$ 7.4, permeabilized using a10 min incubation with $0.1 \%$ TritonX-100, and washed again with PBS. Cultures were then incubated in 3\% normal goat serum in PBS with $0.1 \%$ Tween 20 for at least 1 hour at room temperature. Blocking was followed by incubation with primary antibodies in $1 \%$ goat serum $+0.1 \%$ Tween 20 for at least 3 hours at room temperature. Antibodies against type III $\beta$-tubulin $(1: 100$, Chemicon) and against tyrosine hydroxylase (1:100, Sigma) were used to detect neurons. Antibodies against gamma amino acid decarboxylase (GAD) were used to identify GABAergic neurons (1:1000, Chemicon), anti L-glutamate to detect glutamatergic neurons (1:50, Signature Immunologics), anti glycine to detect glycinergic neurons (1:100, Signature Immunologics) and anti choline acetyl transferase (CHAT) to detect cholinergic neurons (1:100, Chemicon). The cultures were washed in PBS at least 3 times, and incubated with secondary antibodies diluted in $1 \%$ goat serum with $0.2 \%$ Tween 20 for 1 hour at room temperature in the dark. The secondary antibodies were goat anti-mouse FITC (1:200, Sigma) and goat anti-mouse rhodamine (1:200, Boehringer). For double staining, cells were incubated in second primary antibody for required time at room temperature, then washed in PBS/Tween-20 three times for 5 minutes each, then incubated in secondary antibody for 30 minutes at room temperature. For double staining, cells were mixed with both secondary antibodies together. DAPI $300 \mathrm{nM}$ was added for 5 minutes at room temperature, then washed in PBS/Tween-20 for 5 minutes at room temperature then removed, washed and allowed slides to dry completely, then mounted with Prolong Antifade mounting media.

\section{Dopamine Synthesis}

$1 \mathrm{ml}$ of growth media from control or $\mathrm{KCl}$ stimulated ( 50 $\mathrm{mM} \mathrm{KCl}$ for 30 minutes) cultures (to induce dopamine secretion by adding $50 \mathrm{mM} \mathrm{KCl}$ for 30 minutes) was collected. Dopamine was immediately stabilized by adding to the culture media $88 \mu 1$ of $85 \%$ orthophosphoric acid and $4.4 \mathrm{mg}$ of metabisulfite. Samples were sent to an HPLC facility where analysis was performed. Dopamine was extracted from samples using aluminum extraction method and analyzed with a reverse-phase C18 column in a MD-TM mobile phase (Esa Inc). Results were validated by co-elution with dopamine standards.

\section{Pre-Implantation Procedures}

Prior to implantation, cells were removed from the expansion media and matured in the cell differentiation media to begin post-mitotic differentiation. Cells were induced to differentiate for 3 days, then collected by mild trypsinization ( $0.01 \%$ trypsin in Verseen, 5 minutes at room temperature), washed twice with F12/DMEM medium, resuspended in Dulbecco-modified phosphate-balanced salt solution (GIBCO), washed twice again with F12/DMEM medium and sent to the operating room prior to transplantation in a sterile cell incubator at $37^{\circ}$. Differentiation and dopamine synthesis prior to transplantation were analyzed in vitro from a separate batch of mature cells derived from the same process.

\section{Safety Testing}

All specimens were serially tested for sterility over the course of cell expansion and prior to transplantation. Cultures were performed to rule out any viral or bacterial contamination, mycoplasma or endotoxins. Potential tumori- 
genicity was ruled out by transplantation of the stem cell isolates into eight nude mice brains (cerebral cortex and striatum). 200,000 stem cells were transplanted per injection site, and brains were analyzed at 5 months post-transplantation. Serial sections of mice brains were analyzed after hematoxylin-eosin staining. Gross morphological, histological and karyotype studies revealed no tumor formation at the site of implant.

\section{Clinical Protocol}

The patient was entered in the clinical study for autologous neural stem cell transplantation for idiopathic Parkinson's disease. Our clinical protocol followed the guidelines from the Core Assessment Program for Intracerebral Transplantation (CAPIT) protocol. Timed testings (pronationsupination, finger dexterity, stand-walk-sit) and UPDRS scores were administered while "off" and "on" medication. The patient demonstrated a positive response to L-dopa following a practically defined "off" examination. One examination was videotaped pre-operatively and post-operatively. Three separate, baseline independent neurological evaluations and medication regimen remained unchanged over six months prior to transplantation. Baseline Mini-Mental status and full neuropsychometric battery were administered. Preoperative MRI and 18F-DOPA PET scan were obtained within two weeks of surgery. Post-operative clinical assessments were performed at 3, 6, 9, 12, 18, 24, 36, 48 and 60 months by neurological evaluations. Post-transplantation MRI with contrast enhancement and PET scan were obtained at 3 months and 12 months. At 60 months, a brain computerized tomography was obtained.

\section{Functional Imaging}

Fluoro-DOPA PET studies were performed after administration of $10.7 \mathrm{mCi}$ of fluorine-18 L-DOPA intravenously one hour after ingestion of $200 \mathrm{mg}$ of carbidopa. The patient stopped medication for a least $12 \mathrm{~h}$ before the studies. Tomographic images were acquired on a Siemens/CTI PET scanner and were reconstructed with attenuation correction. Parametric images were generated from regional analysis of the caudate and putamen using a cerebellum region as the free unbound F-DOPA activity in plasma. Studies were obtained two weeks prior to implantation, at 3 and 12 months postoperatively.

\section{Stereotactic Micro-Injection}

The second stage of the procedure was performed nine months after harvesting. Under local anesthesia, stereotactic magnetic resonance imaging studies (MRI) were acquired in the Leksell-G stereotactic frame. Surgical planning was made using computerized software, and targets were selected within the left putamen using stereotactic MRI superimposed to the pre-operative Dopa-PET study. Following a single stereotactic craniotomy (burr hole) while awake, 6 microinjections were delivered at a rate of $5 \mu \mathrm{l} /$ minute with a micro syringe mounted on a hydraulic micro-drive. Sterile cellular suspensions containing approximately six million differentiated neural stem cells (neurons and glial cells) were microinjected into six targets, $4 \mathrm{~mm}$ apart, in the left postcommissural putamen. Each trajectory delivered $50 \mu 1$ of cell suspension, or approximately one million cells, over 10 minutes per site. No steroids or immunosuppressants were given during or after surgery. The patient was continued on his medication and sent home one day after the surgery.

\section{RESULTS}

\section{Neural Stem Cell Culture and Expansion}

Neural stem cells were isolated at the time of corticalsubcortical biopsies from several patients and propagated as neurospheres in the presence of epidermal growth factor (EGF) and beta fibroblast growth factor (bFGF) for six months (Figs. 1a and 2). Cells in the neurospheres reproducibly express nestin and musashi mRNA, characteristic markers for neural stem cells, and proliferate with the doubling time of approximately 4 days.

\section{Neural Stem Cell Differentiation}

We differentiated several isolates of human adult neurospheres (AC1, AC2, AC3) and analyzed expression of celltype specific markers $\beta$ III-tubulin, glial fibrillary acidic protein (GFAP), and galactocerebroside (GalC). $11 \%$ to $35 \%$ of differentiated cells consisted of neurons ( $\beta$-III-tubulin + ), $20 \%$ to $49 \%$ of astrocytes (GFAP + ), and $1 \%$ to $3 \%$ of oligodendrocytes $(\mathrm{GalC}+)$ (Table 1). Differentiated neurons (Figs. 1b, c and 3) and tyrosine hydroxylase (TH)-positive cells (Figs. 1d and 4) developed in cultures where growth factors were removed and substituted with a mixture of $10^{-6}$ $\mathrm{M}$ all-trans retinoic acid, $1 \mathrm{mM}$ dibutyryl cyclic AMP, FGF8 (20 ng/ml), and GDNF (20 ng/ml). In addition to dopaminergic neurons, differentiated cultures contain astrocytes, oligodendrocytes and several types of neurons, including gamma-aminobutyric acid (GABA) ergic, cholinergic, glycinergic and glutamatergic neurons (Table 2).

\section{Dopamine Synthesis and Secretion}

Both immunostaining results and dopamine secretion demonstrate the presence of functional dopaminergic neurons in the treated cultures. Reverse-phase HPLC analysis demonstrated synthesis and secretion of dopamine (Table 2). Dopamine concentration in culture media of differentiated cells 5 days after initiation of differentiation was $100 \pm 45$ $\mathrm{pg} / \mathrm{ml}$. Stimulation of dopamine secretion by exposing these cultures to $50 \mathrm{mM} \mathrm{KCl}$ for 30 minutes lead to a approximately three-fold increase in dopamine levels in the culture media $(345 \pm 74 \mathrm{pg} / \mathrm{ml}, \mathrm{n}=3)$.

\section{Stereotactic Micro-Injection}

The characteristics of the differentiated neuronal transplant from this specific patient cell line "AC2" is shown in Table 2. Our pre-clinical studies have shown a cell survival rate of 10 to $30 \%$ at 60 days post-transplantation in rat models. Based on these findings, we could extrapolate that approximately 630,000 neurons, including up to 93,000 dopaminergic and 378,000 GABAergic neurons, from the 6 million cells transplanted in the left putamen, survived the procedure. This number of cells remains well below the estimated number of dopaminergic afferent neurons from the substantia nigra (estimated at 250,000 per hemisphere) needed to fully restore this circuitry. 

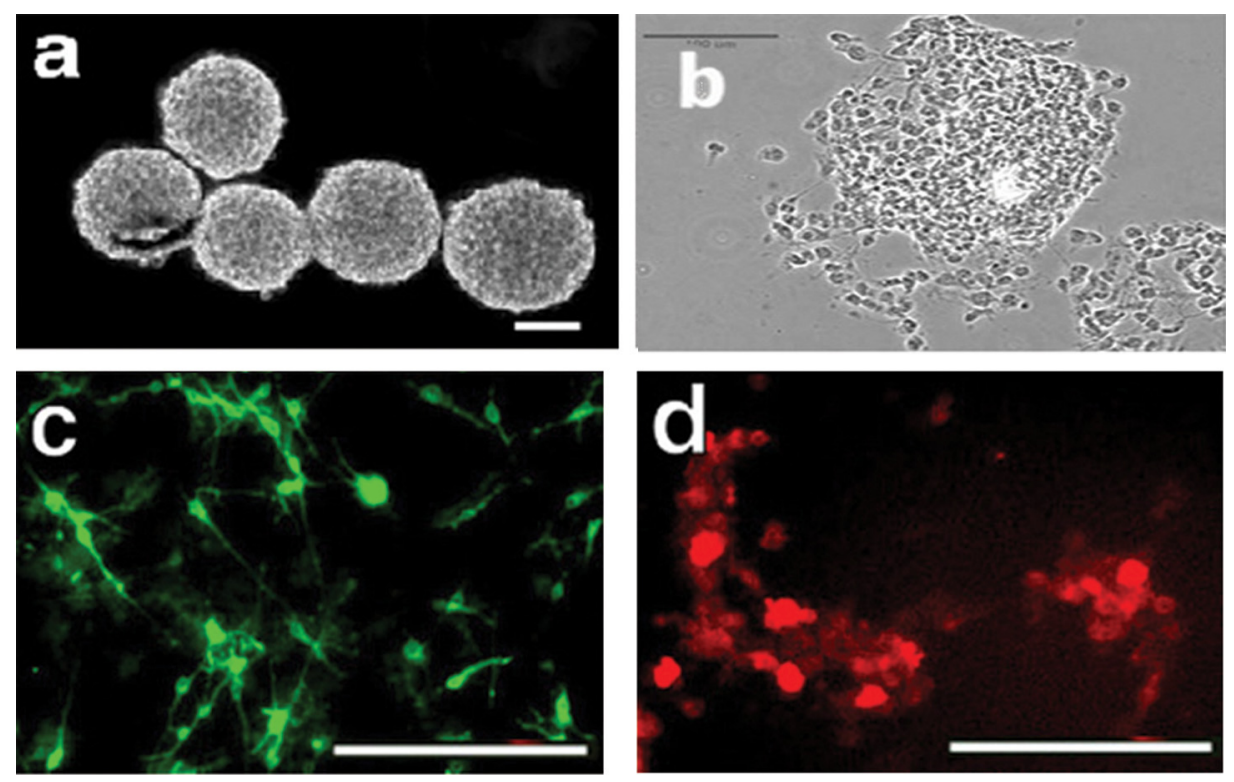

Fig. (1). Differentiation of human neural stem cells in vitro. (a) Phase contrast photomicrograph of neurospheres during expansion. (b) Differentiated neural stem cells seven days after initiation of differentiation with $10^{-6} \mathrm{M}$ all-trans retinoic acid, $1 \mathrm{mM}$ dibutyryl cyclic AMP, FGF8 $(20 \mathrm{ng} / \mathrm{ml})$, and GDNF (20 ng/ml). (c) Fluorescent image of $\beta I I I-$ tubulin positive neurons 7 days after initiation of differentiation. (d) Differentiated TH-immunoflourescent neurons 7 days after initiation of differentiation (BAR $=100 \mu \mathrm{m})$.
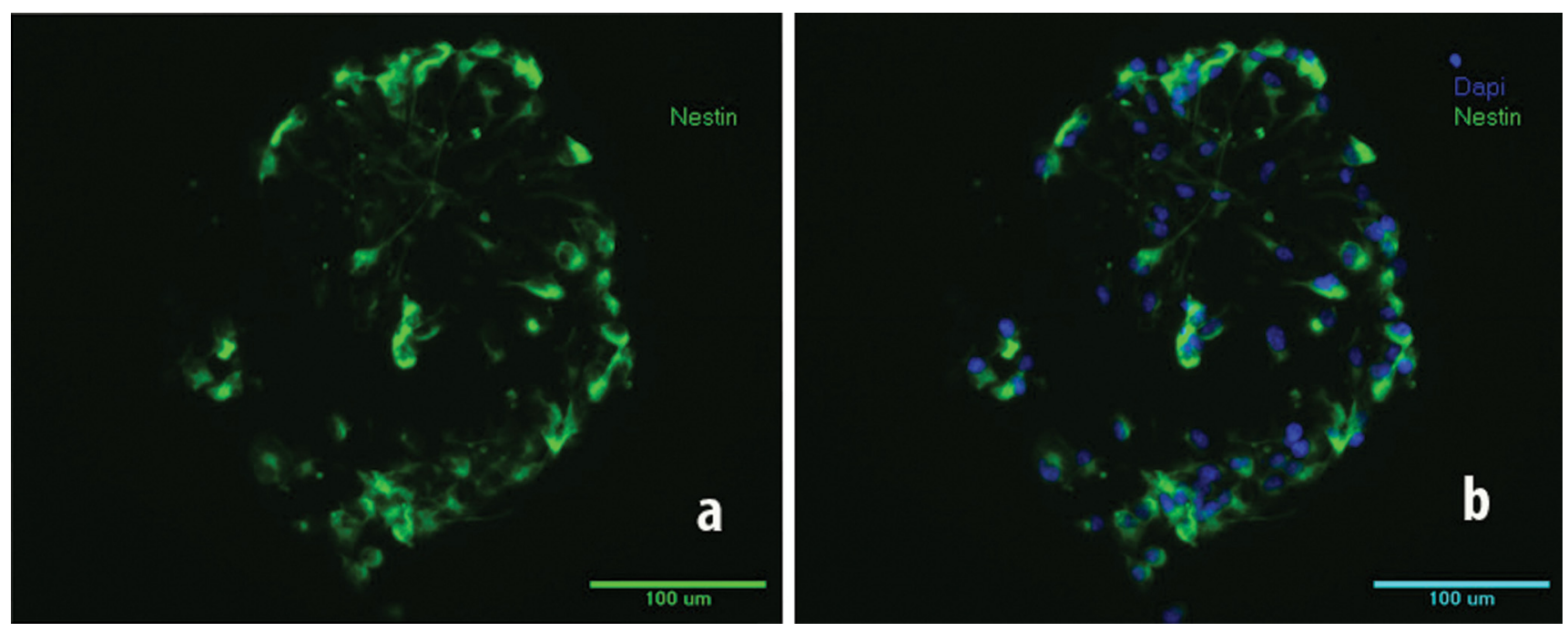

Fig. (2). Human neural stem cells in vitro. (a) Nestin immunostaining of neurospheres during expansion. (b) Nestin and DAPI nuclei staining of human neural stem cells prior to differentiation $(\mathrm{Bar}=100 \mu \mathrm{m})$.

Table 1. Differentiation of Astrocytes, Oligodendrocytes and Neurons from Adult Human Neural Stem Cell Lines from Patient AC2 After Treatment with $10^{-6}$ M AllTrans Retinoic Acid (RA), 1 mM Dibutyryl Cyclic AMP (dBcAMP), FGF8 $(20 \mathrm{ng} / \mathrm{ml})$, and GDNF (20 $\mathrm{ng} / \mathrm{ml}$ )

\begin{tabular}{|c|c|}
\hline $\begin{array}{c}\text { Adult Neural Stem Cell Lines } \\
\text { (Cortico-Subcortical Biopy) }\end{array}$ & AC2 \\
\hline \hline Astrocytes (GFAP+) & $49 \pm 3(\%)$ \\
\hline Oligodendrocytes (Galc+) & $5 \pm 1(\%)$ \\
\hline Neurons (BIII Tubulin+) & $35 \pm 6(\%)$ \\
\hline
\end{tabular}

\section{Clinical Evaluation}

The most significant finding of this study was the continued clinical improvement during the first year, which persisted for the following 36 months, but subsequently declined during the $4^{\text {th }}$ and $5^{\text {th }}$ year. The pre-operative UPDRS score of 37 /60 (“on/off") improved to 7/10 at one year postoperatively $(81 \% / 83 \%)$. The motor UPDRS score before transplantation of 26/41 ("on/off") improved to $2 / 5$ (92\%/ $88 \%$ ) one year after transplant. These improvements persisted at 24 and 36 months after transplantation (Fig. 5). At 3 and 6 months post-transplantation when the thalamic stimulator was turned "off, " the baseline right-sided tremor returned to a pre-operative score of 4 (motor UPDRS tremor rating scale). At 9 months post- and up to 48 months post- 

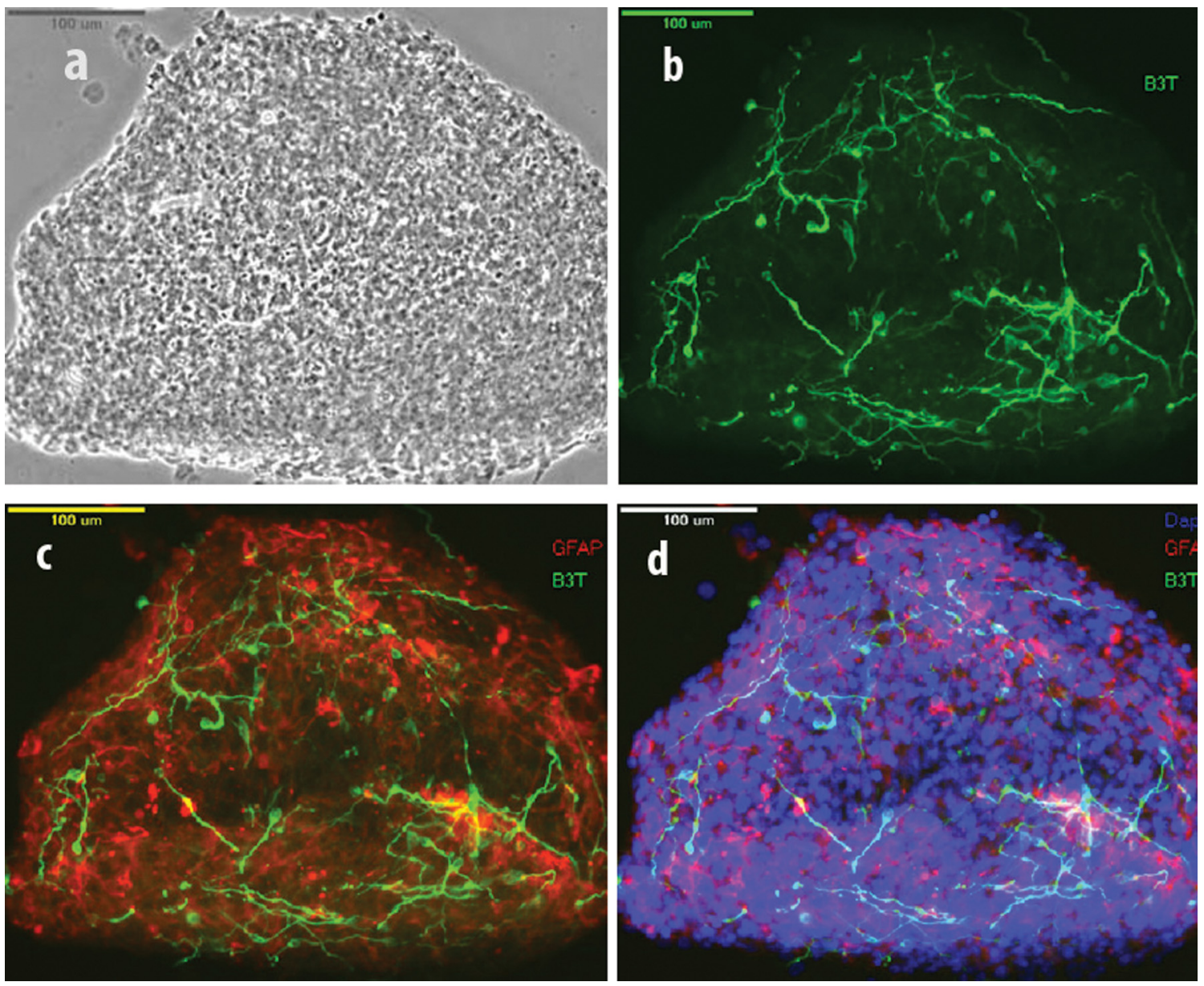

Fig. (3). Differentiation of human neural stem cells in vitro. (a) Phase contrast photomicrograph of neurosphere during expansion. (b) Differentiated neural stem cells three days after initiation of differentiation labeled with $\beta 3 \mathrm{~T}$, (c) Double labeled with GFAP and $\beta 3 \mathrm{~T}$ and (d) DAPI, GFAP and $\beta 3$ T. (Bar=100 $\mu \mathrm{m})$.

transplantation, the tremor score remained at 1 while "off" stimulation and "off" medication. Since the tremor was refractory while "on" medication, the UPDRS improvement while "on" is due to the complete cessation of tremor. The equivalent daily intake of levodopa was reduced to $300 \mathrm{mg} /$ day. At 48 months he began to develop rigidity and slowness of movement on the non-operated side. At 60 months, the implanted side regressed to baseline and the non-operated side continued to progress as reflected by the worsening of his motor scores.

\section{Imaging Studies}

Two weeks before transplantation, the DOPA-PET study showed an asymmetrical deficit in the uptake of the labeled marker, significantly more severe in the left striatum than the right, which correlated with the clinical presentation (Fig. 7a). At three months post-operatively, the dopamine-uptake within the left putamen increased $55.6 \%$ above baseline, while other regions of interest (right putamen, left and right caudate) remained within their initial value (Fig. 7b). At twelve months after surgery, the left putamen uptake value remained at $33.2 \%$ above baseline and the contralateral putamen increased at $28 \%$ above baseline; other striatal regions remained unchanged (Fig. 6). The post-operative MRI at 3 months and one year showed no structural changes within the implanted putamen, no enhancing changes, hypodensity

Table 2. Characterization of Differentiated Neural Stem Cells Derived from AC2 Cell Line Prior to Implantation. Dopaminergic Cells, Dopamine Secretion at Baseline and After Stimulation Demonstrates Functionality In Vitro. A Large Proportion of GABAergic Cells is Represented with other Neuronal Phenotypes within the Injected Suspension

\begin{tabular}{|c|c|}
\hline Differentiated Neurons from AC2 Cell Line & $\mathbf{3 5} \pm \mathbf{6}(\%)$ \\
\hline \hline Tyrosine Hydroxylase(+) neurons & $15 \pm 3(\%)$ \\
\hline DopaDecarboxylase (+)neurons & $12 \pm 3(\%)$ \\
\hline Dopamine baseline secretion $(\mathrm{pg} / \mathrm{ml})$ & $100 \pm 40$ \\
\hline Dopamine secretion after stimulation $(\mathrm{pg} / \mathrm{ml})$ & $350 \pm 82$ \\
\hline GABA neurons & $60 \pm 8(\%)$ \\
\hline Glutamate neurons & $20 \pm 3(\%)$ \\
\hline Cholinergic neurons & $2 \pm 1(\%)$ \\
\hline Glycine neurons & $3 \pm 1(\%)$ \\
\hline
\end{tabular}



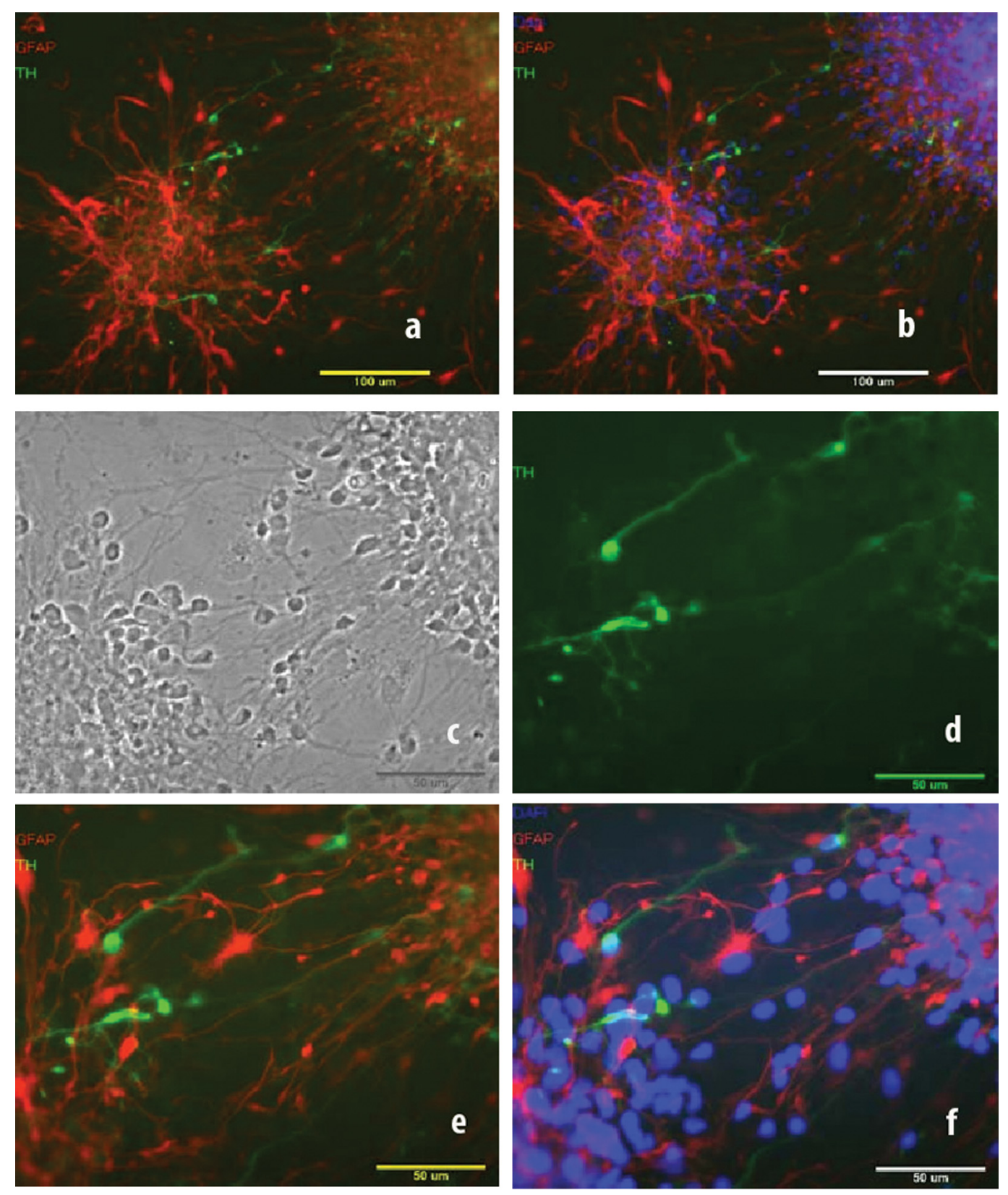

Fig. (4). Differentiation of human neural stem cells in vitro: (a) and (b) Double staining with GFAP, TH and GFAP,TH and DAPI (Bar $=100 \mu \mathrm{m}$ (c) Phase contrast photomicrograph at 10 day following differentiation. (d,e,f) TH-immunostaining of differentiated dopaminergic neurons, GFAP and TH double staining and DAPI, GFAP and TH immunostaining $(40 \mathrm{X})(\mathrm{Bar}=50 \mu \mathrm{m})$.

or mass lesion suggestive of tumor formation. At 60 months, a brain computerized tomography again showed no structural changes in the implanted putamen.

\section{DISCUSSION}

The use of autologous differentiated neural stem cells for Parkinson's disease in humans has not previously been documented. In the present study, we demonstrate prolonged clinical regression after autologous differentiated neural stem cell therapy for Parkinson's disease at five-years postoperatively.

Neural transplantation for Parkinson's disease aims at replacing the loss of nigrostriatal neurons. Following the equivocal results of two double-blind studies using fetal mesencephalic tissue [4,23], different cellular therapeutics have since been investigated to better refine and characterize the types of neural replacement. The potential use of neural stem cells as therapeutic agents for neurodegenerative disorders has been extensively reviewed elsewhere [24-26].

Neural stem cells are present in adult avian and mammalian brains $[12,13,15,27]$. Active neurogenic regions showing continuous dynamic neural cell production have been shown in the granular zone of the hippocampal dentate gyrus and the periventricular subependymal zone $[28,29]$. Nonneurogenic regions of the brain can harbor "dormant" neural progenitor cells in many regions, including the white matter, 


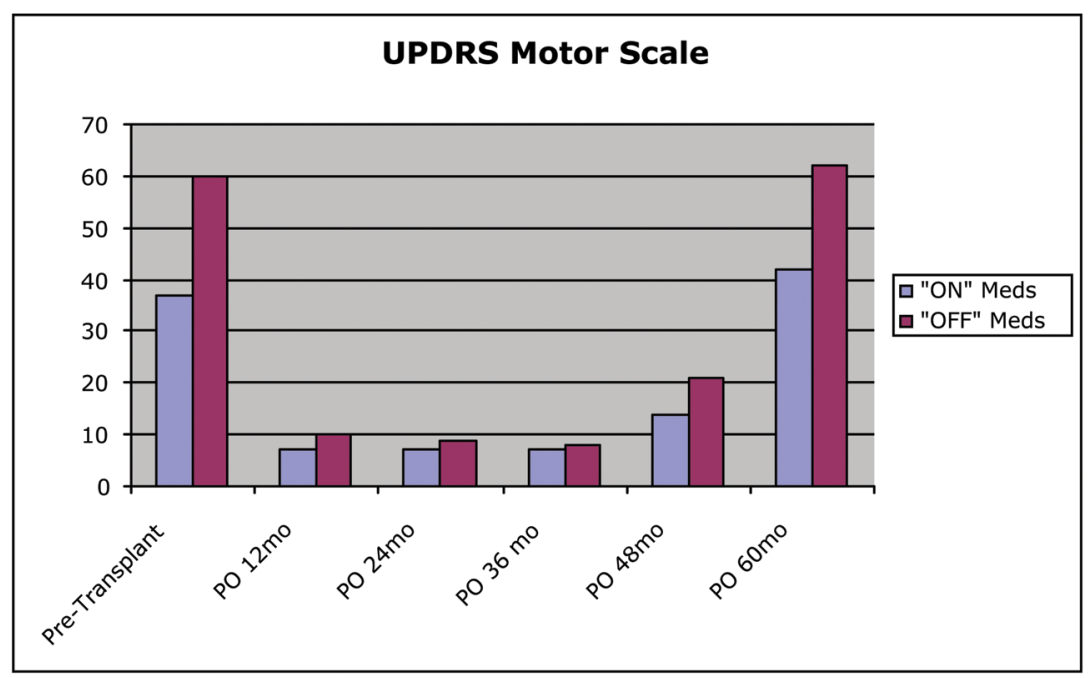

Fig. (5). Clinical response to autologous neural stem cell and differentiated neuron micro-injections. UPDRS motor scale. The left bars show the motor score (UPDRS motor) while "on" medication with the thalamic stimulation "off." The right bars are motor score while "off" medication, thalamic stimulation "off".

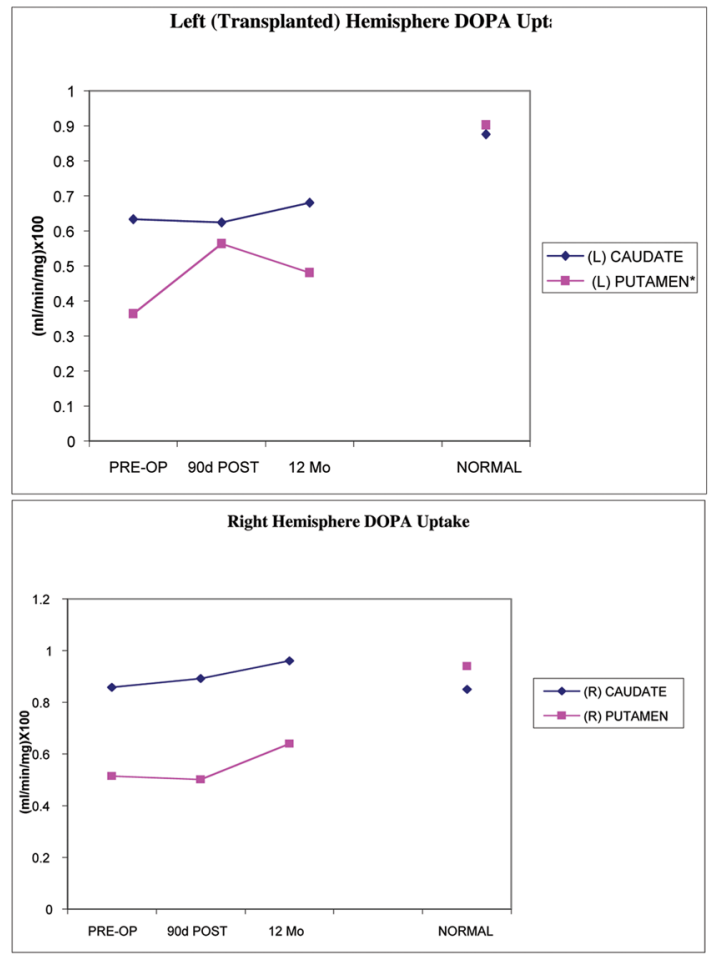

Fig. (6). Graphs depicting the semi-quantitative metabolic changes of 18fluoro-DOPA over time of striatal structures pre-and post transplantation.

demonstrating self-renewal and multipotency in vitro [14, 30]. Active neocortical neurogenesis remains controversial [31-33] and may depend on local permissive factors. Local microenvironment has been modified in vivo to induce intrinsic neurogenesis [34] but has not been shown yet to have significant neural repair potential.

Multiple neural stem cell subpopulations have regional specificity and potential for therapeutic application [25]. We have identified neural stem cells within the prefrontal cortical and subcortical region during neurosurgical procedures.
These human adult neural stem cells have certain similarities to embryonic neural stem cells in their multipotentiality, proliferation rate, and expression of regulatory genes [17]. We believe these neural stem cells harvested from the prefrontal cortical-subcortical region represent radial glial progenitor stem cells originating from the primitive neuroepithelium $[35,36]$.

Our current study is based on the selective isolation, expansion and differentiation of these neural stem cells with epigenetic factors, replicating certain steps of human neuro- 

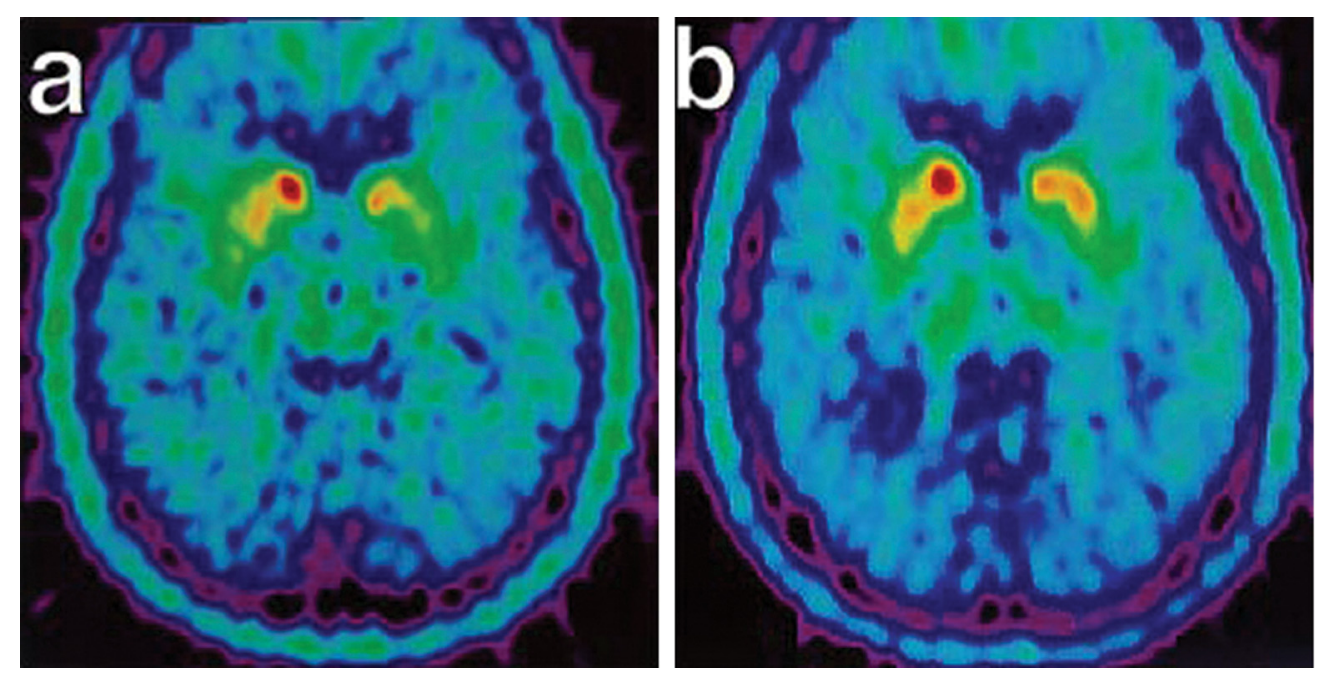

Fig. (7). 18-Fluoro-DOPA Positron Emission Tomography Studies. (a) Pre transplant uptake study showing decrease nerve terminal density in the striatum, worse on left (right on picture), consistent with Parkinson's disease. (b) Post transplant study with increase activity of marker at the site of micro-injections in left putamen.

genesis by inducing a shift in the expression pattern of homeobox genes in vitro. Unlike embryonic stem cells, adult neural stem cells have a committed path to the formation of tissue from the central nervous system. In addition, embryonic stem cells have previously been shown to differentiate into neural cell types, but can maintain delayed expression of other phenotypes and can form teratomas [37].

The controlled manipulation of gene expression of adult neural stem cells in vitro allows for the induction of neuronal fate and phenotypic differentiation. Thus, several millions of committed post-mitotic autologous neurons are produced and characterized prior to transplantation. Safety studies during the expansion phase minimize risks of tumorigenicity and transmission of infectious vectors. Several refinements of these techniques, with the recent understanding of molecular events of developmental and regenerative neurogenesis, will optimize these processes.

Unlike the host residual nigrostriatal neurons, regenerated dopaminergic neurons have not been exposed to years of chronic oxidative stress or other predisposing factors leading to neurodegeneration. In this study, $15 \%$ of differentiated neurons were characterized in vitro as functional dopaminergic neurons, with evidence of dopamine synthesis and secretion. This reflects a significant increase over fetal mesencephalic tissue, containing an estimated $5 \%$ of viable dopaminergic neurons [24]. Until intrinsic neurogenesis can be triggered in vivo in humans and new cells can be induced to migrate, differentiate, and integrate spontaneously into damaged circuits, therapeutic neuroregeneration will require direct delivery of differentiated neurons into specific intracerebral targets.

The exact survival rate and possible integration of implanted differentiated neural stem cells in this patient remain unknown. The clinical improvement observed here is disproportionate to the number of surviving dopamine neurons predicted from our cell survival studies in animals. On the other hand, the contribution of GABAergic cells to the clinical outcome and tremor control is probably important. GABAergic cells play a major role by their local effect on striatal D1 receptors [38], known to be dysfunctional in animal models of Parkinson's disease [39]. Alternatively, implanted GABAergic cells may enhance the direct inhibitory output from the striatum to the overactive motor output of the basal ganglia [40,3]. These findings challenge the pure dopaminergic deficit dogma of Parkinson's studies in both animal and clinical trials, and suggest a chronic striatal deficit or dysfunction of striatal GABAergic neurons in addition to severe dopaminergic cellular loss in human Parkinson's disease.

The therapeutic roles of undifferentiated neural stem cells and neurotrophic factors contained in the injected cell suspension remain unknown. The previously implanted thalamic stimulator had been kept "off" for four years postoperatively and did not contribute to the clinical evaluation or outcome.

The functional imaging studies showed a significant increase in dopamine uptake within the transplanted putamen at three-months post-transplantation. In contrast, other striatal regions of interest, including the non-transplanted contralateral putamen, remained abnormally low, consistent with Parkinson's disease. This increase can represent presynaptic captation of the marker and be correlated with the survival and functionality of transplanted dopaminergic cells [41, 42]. At one year post-implantation, the dopamine uptake in the injected putamen remained at $33.2 \%$ above baseline, suggesting dopaminergic neuron survival. The clinical outcome at one year, however, is disproportionate to these results, contrary to findings in patients receiving fetal tissue $[43,6]$. We also noted contralateral putaminal increase in the dopamine uptake of $28 \%$. Bilateral clinical improvement has previously been documented in certain cases receiving unilateral fetal transplantation [44, 45], but was not necessarily reflected by functional imaging studies. Separately, sequential grafting has been shown to produce contralateral increase of fluorodopa uptake in the caudate nucleus that did not receive the implant by $20 \%$ [46]. Others have noted focal extrastriatal increase in the fluorodopa uptake in early Parkinson's disease patients and this was interpreted as compensatory 
[47]. In our study, the contralateral putaminal increase at one year remains unclear and could also be interpreted as compensatory.

The continued clinical improvement over time could be explained by the non-dopaminergic interaction of the implanted cell suspensions within the host striatum. This therapeutic effect persisted over three years and is much greater than placebo effect demonstrated at one year in another transplantation study [48]. A word of caution about the significance of these results: first, the severe asymmetrical presentation of this case and improvement after treatment magnifies the overall clinical outcome and second, this single case requires additional clinical studies to substantiate our conclusions. The clinical regression at year four and five postoperatively indicates bilateral progression of the disease. Further refinement of the dosage, dose escalation, and a larger clinical trial is currently being planned to insure reproducibility of these findings. This next clinical trial will consist of a prospective randomized controlled study and will compare best medical treatment to autologous neural stem cell therapy for advanced Parkinson's disease. Selection criteria based on severity of the disease and genetic background will be among several other aspects that will be analyzed to provide statistically significant data after primary objectives are met.

\section{CONCLUSIONS}

Neural stem cells can be isolated from the human adult cerebral cortex, expanded in vitro using epigenetic factors, induced to differentiate into dopaminergic, GABAergic and other types of mature neurons, and selectively delivered back to striatal targets without immunosuppressant. Because of their biocompatibility, safety and potential integration into the host striatum, autologous neural stem cell-derived differentiated neurons represent an alternative to current cell therapy aimed at the restoration of the nigro-striatal circuitry in Parkinson's disease.

\section{REFERENCES}

[1] Fearnley J, Lees AJ. Ageing and Parkinson's disease: substantia nigra regional selectivity. Brain 1991; 114: 2283-301.

[2] Jenner P, Olanow CW. Understanding cell death in Parkinson' disease. Ann Neurol 1998; (Suppl 44): S72-S84.

[3] Lang AE, Lozano AM. Parkinson's disease. N Engl J Med 1998; 339: 1044-54.

[4] Freed CR, Greene PE, Breeze RE, et al. Transplantation of embryonic dopamine neurons for severe Parkinson's disease. N Engl J Med 2001; 344: 710-9.

[5] Lindvall O, Rehncrona S, Brundin P, et al. Human fetal dopamine neurons grafted into the striatum in two patients with Parkinson's disease: A detailed account of methodology and 16 month followup. Arch Neurol 1989; 46: 615-31.

[6] Olanow CW. Transplantation for Parkinson's disease; pros, cons, and where do we go from here? Mov Disord 2002; 17: S-15.

[7] Barker RA and Widner H. Immune problems in central nervous system cell therapy. NeuroRx 1 2004; 4: 472-81.

[8] Freed CR. Fetal neural transplantation for Parkinson's disease. In: Rich RR, Ed. Clinical Immunological: Principles and Practice. New York: Mosby 1996: pp. 1677-87.

[9] Kordower JH, Styren S, Clarke M, et al. Fetal grafting for Parkinson's disease: expression of immune marker in two patients with functional fetal nigral implants. Cell Transplant 1997; 6: 213-9.

[10] Hagell P, Piccini P, Bjorklund A, et al. Dyskinesias following neural transplantation in Parkinson's disease. Nat Neurosci 2002; 5: $627-8$.
[11] Boer G.J. Ethical guidelines for the use of human embryonic or fetal tissue for experimental and clinical neurotransplantation and research. J Neurol 1994; 242: 1-13.

[12] Eriksson PS, Perfilieva E, Björk-Eriksson T, et al. Neurogenesis in the adult human hippocampus. Nat Med 1998; 4: 1313-7.

[13] Gage FH, Coates PW, Palmer TK, et al. Survival and differentiation of adult neuronal progenitor cells transplanted to the adult brain. Proc Natl Acad Sci USA 1995; 92: 11879-83.

[14] Palmer TK, Markakis EA, Willhoite AR, et al. Fibroblast growth factor-2 activates a latent neurogenic program in neural stem cells from diverse regions of the adult CNS. J Neurosci 1999; 19: 848797.

[15] Reynolds BA, Weiss S. Generation of neurons and astrocytes from isolated cells of the adult mammalian nervous system. Science 1992; 255: 1707-10.

[16] Kukekov VG, Laywell ED, Suslov O, et al. Multipotent stem/ progenitor cells with similar properties arise from two neurogenic regions of adult human brain. Exp Neurol 1999; 156: 333-44.

[17] Palm K, Salin-Nordström T, Lévesque MF, Neuman T. Fetal and adult human CNS stem cells have similar molecular characteristics and developmental potential. Mol Brain Res 2000; 78 (1-2): 192-5.

[18] Pincus DW, Keyoung HM, Harrison-Restelli C, et al. Fibroblast growth factor2/brain-derived neurotrophic factor -associated maturation of new neurons generated from adult human subependymal cells. Ann Neurol 1998; 43: 576-85.

[19] Vescovi AL, Parati EA, Gritti A, et al. Isolation and cloning of multipotential stem cells from the embryonic human CNS and establishment of transplantable human neural stem cell lines by epigenetic stimulation. Exp Neurol 1999; 156: 71-83.

[20] Björklund A, Stenevi U. Reconstruction of the nigrostriatal pathway by intracerebral nigral transplants. Brain Res 1979; 177: 55560.

[21] Perlow MJ, Freed WJ, Hoffer BJ, Seiger A, Olson L, Wyatt RJ. Brain grafts reduce motor abnormalities produced by destruction of nigrostriatal dopamine system. Science 1979; 204: 643-7.

[22] Lévesque MF, Neuman T. Autologous transplantation of adult human neural stem cells and differentiated dopaminergic neurons for Parkinson's disease. J Neurosurg 2002; 96: 413.

[23] Olanow CW, Goetz CG, Kordower JH, et al. A double-blind controlled trial of bilateral fetal nigral transplantation in Parkinson's disease. Ann Neurol 2003; 54: 403-14.

[24] Freed CR. Will embryonic stem cells be a useful source of dopamine neurons for transplant into patients with Parkinson's disease? Proc Natl Acad Sci USA 2002; 99: 1755-7.

[25] Goldman S. Stem and progenitor cell-based therapy of the human central nervous system. Nat Biotechnol 2005; 23: 862-71.

[26] Isacson $O$. The production and use of cells as therapeutic agents in neurodegenerative diseases. Lancet Neurol 2003; 2: 417-24.

[27] Paton JA, Nottebohm F. Neurons generated in the adult brain are recruited into functional circuits. Science 1984; 225: 1046-8.

[28] Doetsch F, Caillé I, Lim DA, et al. Subventricular zone astrocytes are neural stem cells in the adult mammalian brain. Cell 1999; 97 . 703-16.

[29] Johansson CB, Momma S, Clarke DL, et al. Identification of a neural stem cell in the adult mammalian central nervous system. Cell 1999; 96: 25-34.

[30] Kondo T, Raff M. Oligodendrocyte precursor cells reprogrammed to become multipotential CNS stem cells. Science 2000; 289: 17547.

[31] Altman J. Are neurons formed in the brains of adult mammals? Science 1962; 135: 1127-8.

[32] Gould E, Reeves A, Graziano MS, Gross CG. Neurogenesis in the neocortex of adult primates. Science 1999; 286: 548-52.

[33] Rakic P. Neurogenesis in adult primate neocortex: an evaluation of the evidence. Nat Rev Neurosci 2002; 3: 65-71.

[34] Magavi S, Leavitt B, Macklis J. Induction of neurogenesis in the neocortex of adult mice. Nature 2000; 405: 951-5.

[35] Alvarez-Buylla A, Garcia-Verdugo JM, Tramontin AD. A unified hypothesis on the lineage of neural stem cells. Nat Rev Neurosci 2001; 2: 287-93.

[36] Tamamaki N, Nakamura K, Okamoto K, Kaneko T. Radial glia is a progenitor of neocortical neurons in the developing cerebral cortex. Neurosci Res 2001; 41: 1-60.

[37] Björklund LM, Sánchez-Pernaute R, Chung S, et al. Embryonic stem cells develop into functional dopaminergic neurons after 
transplantation in a Parkinson's rat model. Proc Natl Acad Sci USA 2002; 99: 2344-9.

[38] Graybiel AM. Neurotransmitters and neuromodulators in the basal ganglia. Trends Neurosci 1990; 13: 244-54.

[39] Gerfen CR. D1 Dopamine receptor supersensitivity in the dopamine-depleted striatum animal model of Parkinson's disease. Neuroscientist 2003; 6: 455-62.

[40] Albin RL, Young AB, Penney JB. The functional anatomy of basal ganglia disorders. Trends Neurosci 1989; 2: 366-75.

[41] Piccini P, Brooks DJ, Bjorklund A, et al. Dopamine release from nigral transplants visualized in vivo in a Parkinson's patient. Nat Neurosci 1999; 2: 1137-40.

[42] Remy P, Samson Y, Hantraye P, et al. Clinical correlates of [18-F] fluorodopa uptake in five grafted parkinsonian patients. Ann Neurol 1995; 38: 580-8.

[43] Lindvall O. Cerebral implantation in movement disorders: state of the art. Mov Disord 1999; 14: 210-205.
[44] Defer GL, Geny C, Ricolfi F, et al. Long-term outcome of unilaterally transplanted parkinsonian patients. I. Clinical Approach. Brain 1996; 119: 41-50.

[45] Pechanski M, Defer G, N'Guyen JP, et al. Bilateral motor improvement and alteration of L-dopa effect in two patients with Parkinson's disease following intrastriatal transplantation of foetal ventral mesencephalon. Brain 1994; 117: 487-99.

[46] Hagell P, Schrag A, Piccini P, et al. Sequential bilateral transplantation in Parkinson's disease. Effects of the second graft. Brain 1999; 122: 1121-32.

[47] Rakshi JS, Uema T, Ito K, et al. Frontal, midbrain and striatal dopaminergic function in early and advanced Parkinson's disease; A 3D [18F]dopa-PET study. Brain 1999; 122: 1637-50.

[48] Freeman TB, Willing A, Zigova T, et al. Neural transplantation in Parkinson's disease. Adv Neurol 2001; 86: 435-45.

Received: December 11, 2008

Revised: January 13, 2009

Accepted: January 26, 2009

(C) Lévesque et al.; Licensee Bentham Open.

This is an open access article licensed under the terms of the Creative Commons Attribution Non-Commercial License (http: //creativecommons.org/licenses/ by-nc/3.0/) which permits unrestricted, non-commercial use, distribution and reproduction in any medium, provided the work is properly cited. 